RAEIC, Revista de la Asociación Española de Investigación

\title{
Televisión pandémica: algunas características sobre la programación de aire del área metropolitana de Argentina
}

\author{
Pandemic television: some characteristics about the air programming of
} the metropolitan area of Argentina

Heram, Yamila

Universidad de Buenos Aires (UBA)

yaheram@yahoo.com.ar

Forma de citar este artículo:

Heram, Y. (2020). “Televisión pandémica: algunas características sobre la programación de aire del área metropolitana de Argentina", RAEIC, Revista de la Asociación Española de Investigación de la Comunicación, vol. 7, núm. 14, 27-53.

https://doi.org/10.24137/raeic.7.14.2

\section{Resumen:}

A partir el aislamiento social, preventivo y obligatorio por la pandemia del coronavirus en Argentina se ha incrementado el consumo de televisión y se ha instalado un único tema de emisión en torno al COVID-19. El objetivo del artículo es realizar un diagnóstico de la televisión de aire del área metropolitana de Argentina en un contexto de crisis sanitaria como el actual. Para ello, en primer lugar, se describen algunas de las características que se reiteran en la televisión, identificamos por un lado la acentuación de algunos aspectos más tradicionales y por el otro la emergencia de nuevas tendencias. 
Para ello también se trabaja sobre la base de fuentes primarias y secundarias. En segundo lugar, se sistematizan y analizan las grillas de programación de los canales de aire a partir de una acotada muestra que comprende una semana de programación que va del domingo 19 al sábado 25 de abril, a un mes de iniciado el aislamiento obligatorio en el país.

Palabras clave: televisión, pandemia, grilla de programación, consumo, panelismo.

\section{Abstract:}

Since the social, preventive and compulsory isolation due to the coronavirus pandemic in Argentina, television consumption has increased and a single issue has been installed around COVID-19. The aim of the article is to carry out a diagnosis of the air television of the metropolitan area of Argentina in a context of sanitary crisis like the current one. To do this, first, some of the characteristics that are reiterated on television are described, on the one hand we identify the accentuation of some more traditional aspects and on the other the emergence of new trends. For this, we also work on the basis of primary and secondary sources. Secondly, the programming grids of the air channels are systematized and analyzed from a limited sample that includes a programming week that runs from Sunday 19 to Saturday 25 April, one month after the mandatory isolation began in the country.

Palabras clave: television, pandemic, programming grid, consumption, panelism.

\section{INTRODUCCIÓN}

A partir del avance de la pandemia por el COVID-19 y el decreto de aislamiento social, preventivo y obligatorio establecido el 20 de marzo de 2020 en Argentina, pero en gran parte del mundo también, las preguntas e intereses de análisis de desplazan hacia las nuevas configuraciones que se están atravesando en todos los planos de la vida, tanto social como individual, económica, política, sanitaria, cultural, educativa y mediáticamente. Es por ello que desde el campo comunicacional nos interesa 
reflexionar sobre el estado actual de la televisión de aire metropolitana a partir de algunas de las modificaciones y peculiaridades del medio en estos momentos: se ha producido una suerte de covidización de la agenda televisiva, las ficciones locales han dejado de producirse, algunos programa de talk-show o espectáculos se han reconvertido en magazines que tratan sobre la pandemia, el encendido de los canales se ha elevado, los médicos y especialistas adquieren una nueva circulación cotidiana por los medios, el panelismo pregunta más que debate, las conferencias de prensa del presidente cada dos semana atraen gran parte de la atención, y la incertidumbre como vector que atraviesa los diferentes discursos sociales se hace omnipresente en la televisión.

En un contexto de aislamiento, los medios de comunicación y las diferentes redes sociales juegan un doble rol, por un lado de ventana al mundo, de compañía, cercanía y comunicación, y por el otro, de desinformación, sobreinformación e imposición de agenda en torno a un único tema. Ahora bien ¿ por qué centrar el análisis en la televisión argentina? La respuesta está en el consumo: es el medio más elegido, en especial por los adultos mayores de 60 años -con un promedio diario de consumo de más de cinco horas- según los datos de Ignis Media Agency (2020). Es por ello que consideramos relevante generar un diagnóstico sobre la televisión de aire de mayor alcance en términos de cantidad de habitantes ${ }^{1}$ (Canal 13, Canal 9, Telefé, América TV y Net TV de gestión privada y de gestión estatal Televisión Pública), no sólo por ser la que tiene mayor accesibilidad sino también porque parte de la población que tiene más riesgos sanitarios ante el avance de la pandemia es la que más la consume.

Este trabajo es parte de una investigación en curso $^{2}$ que en su primera etapa parte de realizar un diagnóstico sobre la televisión de aire del área metropolitana para así en su segunda fase profundizar en la instancia de recepción y posteriormente cruzar ambos

\footnotetext{
${ }^{1}$ Es necesario aclarar que los canales analizados pueden ser captados por aire solamente en la Ciudad Autónoma de Buenos Aires (CABA), el Área Metropolitana de Buenos Aires (AMBA) y parte de la provincia de Buenos Aires. Para el resto del país esos canales solamente se distribuyen por sistema de cable. Teniendo en cuenta esta consideración es que en el artículo hacemos referencia a los canales de aire del área metropolitana. En Argentina la televisión de aire está conformada por 44 canales. Para más información se puede acceder al informe Media Ownership Monitor Argentina (2019).

2 Datos del proyecto de investigación que por motivos de anonimato no figuran en esta versión.
} 
análisis. Apremiados por la coyuntura actual, en un contexto crítico como el que estamos atravesando, el aporte de este escrito reside en analizar la televisión de aire del área metropolitana de Argentina, para ello, en primer lugar, se describen algunas de las características que se reiteran, identificamos por un lado la acentuación de algunos aspectos más tradicionales y por el otro la emergencia de nuevas tendencias. Para ello también se trabaja sobre la base de fuentes primarias y secundarias. En segundo lugar, se sistematizan y analizan las grillas de programación de los canales de aire a partir de una acotada muestra que comprende una semana de programación (del domingo 19 al sábado 25 de abril), a un mes de iniciado el aislamiento obligatorio en el país. Sistematizar las características y tendencias actuales de la televisión nos permite aportar desde el campo comunicacional en la discusión sobre los medios en situación de crisis.

El artículo está organizado en un apartado metodológico, seguido por una breve caracterización de las tendencias de la televisión actual y a continuación un análisis de las grillas de programación de los canales. Por último, compartimos las principales conclusiones.

\section{METODOLOGÍA}

Partimos de entender que la televisión es un agente clave en la vida de las personas, la agenda televisiva (Wolf, 1987) construye un temario que opera en la mirada que se tiene del entorno. Hall (1981) afirma que la televisión es un medio de comunicación y un objeto que articula representaciones significativas. Asimismo, y siguiendo los datos ofrecidos por la última Encuesta Nacional de Consumos Culturales y Entorno Digital de 2017, el 95\% de la población argentina mira televisión, siendo el medio del sector audiovisual más elegido. Actualmente existe una amplia literatura que problematiza y discute sobre la situación contemporánea de la televisión, en torno a si "está muriendo" o "entrando en una nueva fase" (Carlón, 2016, p. 77). Hay un punto en el que diversos autores (Verón, 2009; Scolari y Carlón, 2009; Piscitelli, 2009; Valdettaro, 2010) coinciden: el desplazamiento hacia otras formas de consumo a partir de las múltiples pantallas, los servicios de streaming on demand, que se manifiestan -en menor o mayor medida- en intereses transitorios de consumo y personalización de la recepción. No 
obstante, consideramos que la televisión en un contexto como el actual de aislamiento social preventivo y obligatorio sigue siendo un medio que, como los datos lo demuestran, es consumido por gran parte de la población en especial los adultos mayores, de allí nuestro interés en realizar un análisis integral de la televisión contemporánea.

El diseño metodológico de la investigación se organiza en la articulación de distintas herramientas analíticas. En primer lugar, a partir del visionado de la televisión -desde los primeros anuncios presidenciales por la pandemia (12/03/20) a la actualidad- se describen algunas de las características que se reiteran. Identificamos dos tendencias, la acentuación de algunos aspectos más tradicionales y la emergencia de nuevas características. Para ello también se trabaja sobre la base de fuentes primarias y secundarias lo que permite complementar el análisis. Cabe aclarar que los ejemplos citados a lo largo del artículo tienen por objetivo ilustrar parte de lo mencionado sin la exhaustividad en la construcción de un corpus acotado, por el contrario, a partir de haber realizado un visionado de más de dos meses de la televisión de aire del área metropolitana, es que se han detectado las características predominantes del funcionamiento televisivo.

En segundo lugar, se sistematizan y analizan las grillas de programación de los canales América TV, Canal 13, Canal 9, Telefé, Net TV y Televisión Pública. Se replica una metodología ya utilizada en trabajos previos (Heram, 2018) sobre la base de la propuesta metodológica de Orza (2002). Se seleccionó una acotada muestra que comprende una semana de programación que va del domingo 19 al sábado 25 de abril, a un mes de iniciado el aislamiento social, preventivo y obligatorio (ASPO). El corte semanal es la unidad mínima de análisis, ya que la grilla televisiva se organiza semanalmente en relación con los tiempos de la cotidianeidad social (Martín Barbero, 1987). La propuesta metodológica consiste en un modelo integral para el análisis de la programación televisiva que permite acceder a una catalogación genérica y caracterización de las unidades discursivas de la grilla. Se llevó a cabo, en primer lugar, un barrido por cada día de la semana de la grilla con el propósito de obtener los datos para el análisis. La información registrada en el barrido fue la siguiente: canal, día de la 
semana, segmento horario, nombre del programa, tipo de discurso, género al que pertenece, país de origen del producto, transmisión en directo o grabado. Para realizar el registro de la programación nos basamos en la información ofrecida en las páginas web de cada emisora. En cuanto al género que corresponde a cada programa optamos por mantener la denominación que la propia grilla propone (lo cual no queda exento de discusión). Los ejes de análisis de la grilla son: promedio semanal de tiempo de emisión por contenidos referenciales, ficcionales e híbridos; géneros que predominan en cada uno de ellos; programación en el horario de prime time, país de origen del producto transmitido, porcentaje de tiempo de emisión en directo o grabado.

Esta investigación es de corte cualitativo (Denzin y Lincoln, 2003), se describen las características de la televisión de aire del área metropolitana de Argentina para así identificar invariantes, constantes que sólo son posibles en un análisis cultural de la oferta televisiva, además se complementa con datos cuantitativos producidos por la sistematización de las grillas de programación. De esta manera los datos obtenidos permiten caracterizar a la programación televisiva en tiempos de crisis sanitaria como el actual.

\section{IMPACTO EN EL MODELO DE NEGOCIO}

\subsection{ALGUNAS CONSIDERACIONES SOBRE LA TELEVISIÓN}

La relevancia de acercarnos al análisis de la televisión reside en tanto que son los medios de comunicación los agentes privilegiados para el manejo y generación del insumo para la organización colectiva de las prácticas sociales cotidianas: la información, el peso de las agendas, los mecanismos de "concientización", los dispositivos de valoración de lo que está bien o lo que está mal. Según el informe realizado por el grupo de investigación Comunicación Política y Seguridad de la Universidad de Buenos Aires “¿Cómo nos informamos en cuarentena?" (2020), a partir de los 45 años la televisión es el canal noticioso más relevante; en la misma línea el informe "Navigating the 'Infodemic': How People in Six Countries Access and Rate News and Information about Coronavirus" (2020) realiza un relevamiento sobre el acceso a la información en seis países, entre 
ellos Argentina, y entre sus conclusiones menciona que "la televisión e Internet son la forma más popular de recibir noticias" (p. 8).

La crisis sanitaria que desató la pandemia ha acaparado la agenda informativa. Según informe del Consejo Nacional de Investigaciones Científicas y Técnicas (CONICET) en Ciencias Sociales, por primera vez en cuatro años "un tema por fuera de la Política y la Economía se sitúa en el tope de la agenda mediática" (2020, p. 130) y en cuanto a la evolución de los temas en la agenda de marzo "el Covid-19 acapara 9 de cada 10 noticias que se publican en los principales medios digitales del país" (2020, p. 132). Los programas de la televisión abierta han orientado sus recursos para la cobertura. Se advierte una mayor presencia del presidente, se dejó de producir ficción local, hay más médicos en la pantalla, algunos programas de talk show y espectáculos se ha reorientando hacia el magazine en torno al COVID-19, el deporte ocupa menos horas de emisión y el foco de atención oscila entre la cantidad de contagios y decesos en el país y en el extranjero, como en los métodos preventivos para evitar la transmisión, paulatinamente, con el correr de los días, el foco de atención se ha ido desplazando al plano económico y sus consecuencias.

Los canales de aire aquí analizados se caracterizan por ofrecer una programación generalista y de competencia entre las emisoras. A partir del visionado, haciendo foco especialmente en los géneros no ficcionales, es que nos interesa describir algunas de las características de la televisión en este contexto, para ello las organizamos según el criterio de lo tradicional y lo novedoso, es decir aquellos aspectos que vienen de larga data y continúan aggiornados a este nuevo escenario y aquellos que podrían observarse como lo novedoso.

\subsubsection{Características tradicionales}

\section{La televisión, la ciencia y el discurso médico}

Los tiempos de la televisión y los de la ciencia podríamos ubicarlos en las antípodas, ya lo ha mencionado Bourdieu (1996) en cuanto a lo velocidad de la televisión y la ausencia de argumentación a partir de sus "pensadores rápidos", con mensajes de fuerte 
impacto. Por el contrario, la ciencia y sus avances requieren de mayor tiempo, contrastes, pruebas y contrapruebas, lo que genera que no haya algo nuevo para decir cada día, además el discurso científico necesita tiempo en los medios de comunicación para desarrollar las ideas, argumentar y explicar, estos tiempos, en reiteradas ocasiones, no son compatibles con las necesidades del medio.

Estos dos mundos se cruzan en el espacio mediatizado no sin tensión. Estamos en un momento en el que los avances de la ciencia es tema constante de preocupación y ocupación por parte de los medios, ello genera en muchas ocasiones expectativas desmedidas, así como se opuesto, frustración e incertidumbre ante la ausencia de una eminente solución por la creación de una vacuna. Para citar un ejemplo de público conocimiento, la cantidad de horas de pantalla y lugar en los portales de noticias que se le otorgó al científico francés Didier Raoult por el uso de la hidroxicloroquina como posible solución ${ }^{3}$.

Creemos que en la televisión actual se produce una doble tensión en torno al discurso científico y el discurso médico. Por un lado, coincidimos con Fernández (2020) en que: "la presencia distinguida -en los propios paneles, y en cada uno de ellos- de infectólogos y epidemiólogos que, por sus características, no se confunden en el magma panelista. Tienen su conocimiento específico y hablan desde él" (p. 17). Por el otro también encontramos, en especial en los programas de magazines, que muchos médicos ofician de panelistas. Convocados como voz autorizada y en su calidad de expertos en salud, en algunas ocasiones aportan datos sobre prevención, situación y avances del COVID-19 y en muchas otras se los ve en programas de dos horas de duración, sentados cual panelista, y en un ping-pong de temas que se tratan, haciendo intervenciones salteadas que no duran más de treinta segundos y de escaso aporte en materia de información y prevención.

Algunos parecieran ya expertos en los tiempos de la televisión, confunden su rol con el del panelista. Podemos encontrar escenas como la siguiente: programa Cortá por

\footnotetext{
3 Para mayor información se puede acceder a: https://www.infobae.com/america/mundo/2020/05/15/el-cientificofrances-que-promueve-el-uso-de-la-hidroxicloroquina-descarto-una-segunda-ola-de-contagios-la-epidemia-decoronavirus-esta-terminando/
} 
Lozano (Telefé, de lunes a viernes de 14:30 a 17:00. 16 de marzo de 2020), en el piso se encuentran la conductora Verónica Lozano y los panelistas, como invitado el médico Guillermo Capuyo quien oficia como la voz del saber, y el panelismo, reconvertido a través del género de la entrevista realiza preguntas. Una vez pasada la ronda de consultas se comienza a tratar otro tema en torno a Miguel Ángel Paz, la persona que estaba en cuarentena - por haber llegado de un viaje al exterior- y agredió al encargado de la seguridad de su edificio, las imágenes de dicha agresión se viralizaron y llegaron a los medios. A partir del tratamiento de este acontecimiento, el médico actúa como panelista preguntando y opinando desde el sentido común, algunas de sus intervenciones son:

Voy a opinar pero no desde lo médico, esta persona seguramente tiene antecedentes de violencia, son los típicos infractores, los tipos que ponen la música a toda hora, es un fenotipo, algo característico de este tipo de personas que no acatan la orden y le importa un pito lo que vos pensás.

Le puedo hacer una pregunta yo a Paulo, Paulo, las personas que violan la cuarentena (...) qué hacemos con esa persona, dónde la llevamos, pero si tenemos 50, 100, 200 personas que la violan.

Mi mujer me decía hoy, nosotros vivimos en un barrio cerrado, que estaba en el supermercado dentro del barrio una persona que había viajado y no lo quisieron denunciar porque tenía miedo que fuese poderoso. No hay que denunciarlo. Yo lo voy a denunciar.

El caso citado ejemplifica como los saberes se funden y confunden, y por momentos encontramos panelista que ofician de médicos y médicos que ofician de panelistas.

\section{Panelismo}

No es novedoso afirmar que los programas no ficcionales - muchos de ellos en formato de panelismo- tienden a la construcción melodramática de los acontecimientos y al sensacionalismo a través de técnicas de montaje y la construcción de binomios 
dicotómicos es una constante -economía o salud, Suecia o Noruega ${ }^{4}$, barbijos sí / barbijos no-. Rincón (2010) menciona que "nos comportamos / explicamos mejor desde la lógica de la telenovela y el melodrama que desde la argumentación política: menos opinión pública argumentativa, más democracia emocional, espectacular y entretenida y amorosa" (p. 15). El panelismo es una estética discursiva que ocupa muchas horas de pantalla y atraviesa diferentes géneros televisivos (actualidad, magazine, espectáculo, deporte, entre otros); ello profundiza una tendencia que viene desde hace varias décadas ${ }^{5}$ que es la disolución de los géneros televisivos tradicionales.

Entendemos que los programas en que predomina el panelismo, por la misma composición diversa del panel, por la propia figura del conductor, por lo híbrido de su contenido, tienen como destinatarios a colectivos más amplios que los que componen los círculos de consumidores intensos y activos de información política (Autor, xxxx). Partimos de entender que los discursos mediáticos no interpelan a los individuos en tanto que individuos -como unidades aisladas - sino como "nudo" de pertenencias. El valor de un discurso mediatizado no estriba sólo en la función de agenda (es decir, en los criterios de inclusión/exclusión de temas, o en la propia tematización de los fenómenos que aborda), o en su línea editorial, sino en las formas de comunidad que asume, en cómo genera y regenera formas del nosotros y, por lo tanto, formas de representación. En el caso de los programas de panelismo, este fenómeno se torna particularmente importante, el panelismo multiplica, en superficie, las voces, los puntos de vista, los roles representativos, pero no está claro que esto redunde en una oferta de identidad plural. Las preguntas que se ciernen sobre todo contrato de representación (quién habla, en nombre de quién habla) son más complejas de responder cuánto menos unificado el discurso.

\footnotetext{
${ }^{4}$ Hacemos referencia a la utilización, por parte del presidente Alberto Fernández en una conferencia de prensa (8/05/2020), del ejemplo de estos dos países como contraste en las decisiones políticas y económicas sobre cómo actuar ante la pandemia.

${ }^{5}$ La tendencia al show periodístico es introducida en la televisión argentina por Carlos Montero en 1966, en el programa Telenoche por Canal 13 conducido por Mónica Cahen D’Anvers y Andrés Percivale, que inician la tradición dramático teatral de los noticieros.
} 
A partir del relevamiento realizado para el análisis de la grilla de programación podemos afirmar que en la televisión de aire del área metropolitana se emiten 17 programas bajo el formato del panelismo: Canal 13 con dos, Telefe, uno, Net TV tres, Canal 9 seis, América TV cinco y Televisión Pública ninguno por las propias características del canal, al ser una emisora de gestión estatal brinda contenidos diferentes a las señales privadas. El panelismo ocupa un $18 \%$ del total de la programación semanal. Del total de los programas de panelismo un 55\% corresponde al género del magazine, $21 \%$ espectáculos, $20 \%$ actualidad y $4 \%$ entretenimiento. Si bien vale aclarar que muchos de los programas que se denominan magazine tienen un foco más centrado en la actualidad del mundo del espectáculo. Siendo el canal América TV el que se caracteriza por emitir programas de panelismo sobre la actualidad política y Canal 9 y Net TV del mundo del espectáculo.

En relación con lo mencionado, Fernández (2020) observa que en el panel televisivo informativo se presentan ciertos roles relativamente fijos:

Los podemos describir como "actores", pertenecientes a fuerzas actanciales fijas del tipo de: el economista liberal, el desarrollista nacional y popular, el dirigente peronista tradicional, el dirigente peronista $k$, el artista comprometido, el dirigente radical o liberal, el referente de organizaciones sociales, el dirigente trotskista, los consultores y encuestadores, con pronósticos aventurados y que, frecuentemente, no cuentan siquiera con datos (p. 14).

El panelismo aborda el tema del COVID-19 como si fuesen capítulos de una telenovela, genera por un lado una identificación más desde lo melodramático y por el otro contribuye a un mayor desconcierto. Los ejemplos son muchos y variados, sólo a los fines ilustrativos reproducimos esta secuencia del magazine Nosotros a la mañana (Canal 13, de lunes a viernes de 9:00 a 11:00), el 16 de marzo, primer día sin clases en las escuelas y con el tema ya en agenda (previo al aislamiento obligatorio). En el programa se presentan a dos médicos con posiciones antagónicas, uno positivo con respecto al devenir el virus en el país y el otro proclama cuarenta obligatoria de inmediato y es más alarmista. Como si fuese una suerte de box de ring, los conductores 
oscilan entre una y otra posición, más que aclarando e informando queriendo generar identificación con una de las partes. Esta situación no es novedosa en los medios, lo que es novedoso es la situación de aislamiento por la pandemia, el consumo creciente de medios y el estado de alerta permanente, por ello hoy más que nunca los medios deberían repensar estas maneras de comunicar. El panelismo en contexto de pandemia está atravesado por el género de la entrevista, por la circulación de médicos y científicos, y por la incertidumbre en torno al virus.

\section{Vigilancia, punitivismo e historias de vida}

El ASPO tiene su contracara que son los casos de algunos ciudadanos que no cumplen con el aislamiento, ello se convierte en objeto de conversación y denuncia en los programas. Lo que se verifica de manera transversal es la conformación de un discurso que promociona, legitima y normaliza la vigilancia, en términos de Foucault (1978). Tanto el delito como el control son categorías "flexibles" y se aplican sobre aquellos que son peligrosos -actualmente, según los medios, los potenciales portadores de COVID-19 son peligrosos- y por ende pasibles de vigilancia y control estricto. EI pedido de policías en las calles, la "recomendación" de denunciar a aquel que no respeta el aislamiento son algunos de los aspectos que permiten ejemplificar lo planteado. En este sentido son interesantes los aportes realizados por el informe del CONICET, en cuanto a los encuadres que predominan en los medios digitales:

La responsabilización sobre la transmisión de la enfermedad suele recaer más habitualmente sobre los individuos -ciudadanos- que, a través de acciones "irresponsables" y a partir de la violación de las disposiciones del PEN, son sindicados como amenazantes para la salud colectiva. Cuatro de cada diez noticias presentan a ciudadanos individuales como responsables del problema (2020, p. 136).

Los casos que ilustran lo mencionado se reiteran en el día a día de la televisión y de los medios en general, y transmiten un discurso que promociona, legitima y normaliza la vigilancia. Desarrollamos un ejemplo a los fines de ilustrar lo mencionado: móvil del programa Todas las tardes de Canal 9 al inicio de la pandemia (18/03/2020), desde el 
barrio de Parque Chas, en la Ciudad Autónoma de Buenos Aires, el conflicto gira en torno a una vecina que había llegado del exterior y no realizaba el asilamiento obligatorio decretado por el Poder Ejecutivo Nacional, por ello un conjunto de vecinos se reúnen frente a la casa de esta persona para protestar y visibilizar que no está cumpliendo con dicho aislamiento. La función del móvil y el tiempo de pantalla (20 minutos) que se le otorga ofician de vigilancia y control.

También cabe mencionar la analogía con el discurso bélico para hacer referencia al virus, las frases más reiteradas son: "enemigo silencioso", "guerra invisible", "la guerra por la vacuna", "ejército de profesionales de la salud", "vencer esta batalla", "batalla contra el virus", entre tantas otras. La utilización de manera reiterada de estas frases, casi como muletillas, está en sintonía con la idea de vigilancia y control a la que hacíamos referencia.

Otras de las cuestiones que predominan en los medios es el encuadre de las historias de vida, como menciona el informe del CONICET, el "interés humano". El foco está en la vida privada de personas infectadas o varadas en el exterior que relatan sus historias, miedos, dificultades para solventarse económicamente entre otras cuestiones. A través de Skype estas historias anónimas son el complemento de información que circula en la televisión: la familia del psicólogo que quedó varada en Tailandia, la mujer que se recuperó por el uso de la hidroxicloroquina, el cumpleaños del nene en cuarentena al que fueron los policías a saludarlos, la familia del barco amarillo que está en un velero en Brasil y tantas otras más.

\subsubsection{Características emergentes}

\section{Pantalla zoom}

Hasta aquí hemos resaltado algunas de las características tradicionales de la televisión pero ejemplificados con diferentes casos de la coyuntura actual. Ahora bien, también observamos aspectos novedosos a partir de la pandemia, una de ellas es la estética de la pantalla. Con el paso de los días a partir al ASPO, al igual que las videollamadas grupales en las que en diferentes cuadraditos aparecen los integrantes de la llamada, la 
televisión comenzó a utilizar ese mismo recurso y es común observar la pantalla partida en siete, seis o cinco cuadrados, en especial cuando hay un entrevistado vía skype. Las similitudes estéticas con otros dispositivos y pantallas juegan al continuum, estamos viendo televisión con estética zoom, ello genera el efecto de cercanía dado que es una de las vías de comunicación grupales más utilizadas en contexto de aislamiento.

Imagen 1. Fantino a la tarde.

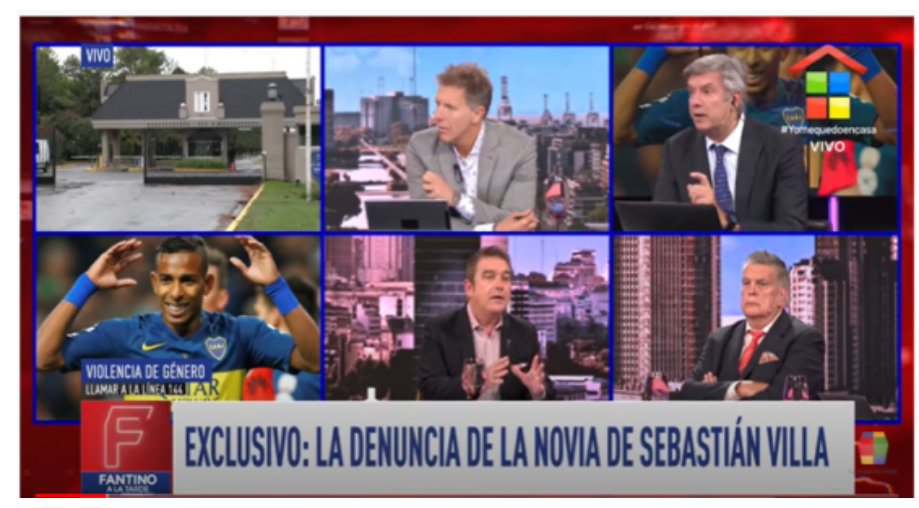

Fuente: América TV.

Imagen 2. $\mathrm{PH}$.

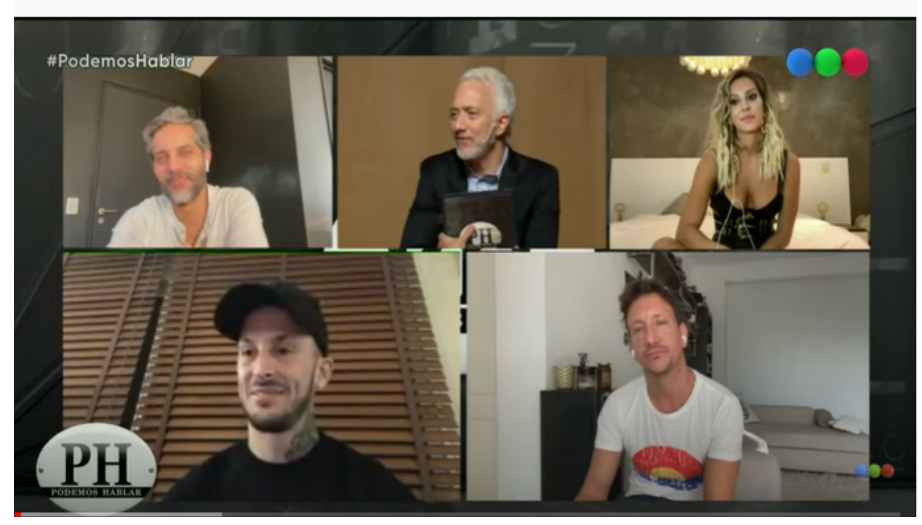

Fuente: Telefe.

\section{Convergencia discursiva}

En una primera etapa del ASPO los medios de comunicación de manera extraordinaria hicieron una convergencia discursiva, con ello hacemos referencia a la unificación de un mensaje común por parte de los diferentes medios. El ejemplo que mejor ilustra este acontecimiento, que con el pasar de los días se disolvió, son las tapas de los principales 
diarios del país que el 19 de marzo titularon al unísono: "Al virus lo frenamos entre todos. Viralicemos la responsabilidad" ${ }^{6}$.

Imagen 3. Tapas de los principales diarios de Argentina

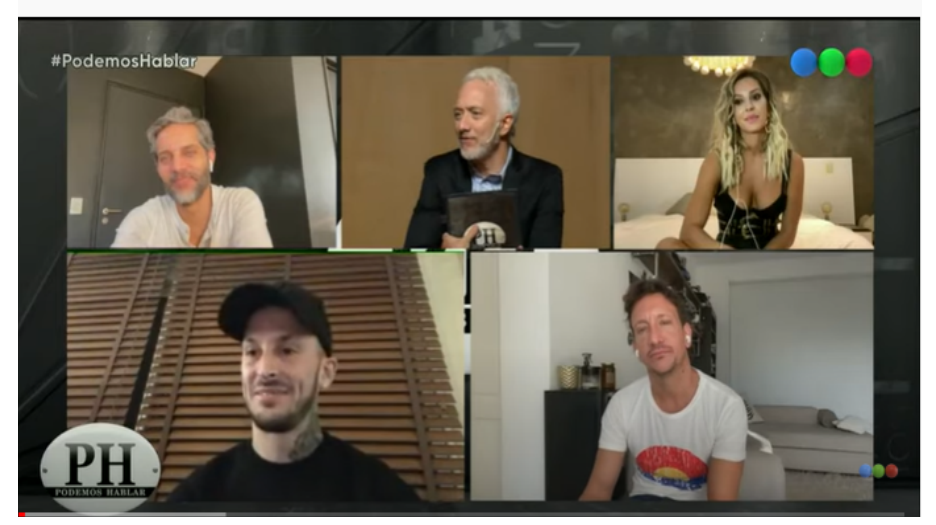

Otro ejemplo de convergencia discursiva es la transmisión de manera conjunta y simultanea por los seis canales de aire del programa solidario Unidos por Argentina (05/04/20). El objetivo fue concientizar frente a la pandemia y recaudar fondos que fueron donados a la Cruz Roja para la adquisición de insumos en los hospitales.

Si bien no se encuentra en la misma línea de lo que observamos como convergencia discursiva en los medios, no es un dato menor la imagen del consenso que también se generó en los primeros anuncios que realizó presidente Alberto Fernández (Frente de Todos). La construcción de la escena de las conferencias de prensa con la participación de diferentes actores políticos demuestra una suerte de unidad y alianza: el 15 de marzo junto con el jefe de gobierno de la ciudad de Buenos Aires, Horario Rodríguez Larreta (Cambiemos) y del gobernador de la provincia de Buenos Aires, Axel Kicillof (Frente de Todos) y el 19 de marzo - día que se anuncia el ASPO- con los gobernadores Gerardo Morales de Jujuy (Cambiemos) y Omar Perotti, Santa Fe (Frente de Todos), además de Rodríguez Larreta y Kicillof.

\section{Consumo}

${ }^{6}$ Tras una iniciativa de la Asociación de Entidades Periodísticas Argentinas (ADEPA). 
La cantidad de horas que la población mira televisión -en especial las personas mayores que son las más vulnerables al virus y las que más deben permanecer en sus casas- genera un efecto que muchas veces puede ser contraproducente, en ese sentido, según datos relevados por el informe "¿Cómo nos informamos durante la cuarentena?", el 69,9\% de los encuestados afirman que "la información sobre la pandemia les produce incertidumbre" (2020, p. 12).

Toda situación de crisis se maneja tanto sobre lo que la crisis genera como sobre la dimensión comunicacional de la crisis, ya que es eso, entre otros factores, lo que vuelve masiva a la crisis. En ese sentido no es un dato menor el aumento del consumo de televisión en el contexto del ASPO. Según el informe Ignis Media Agency (que retoma datos de Kantar Ibope Media, $22 / 04 / 20^{7}$ ), se ha incrementado el consumo de televisión por cable y aire. En cuanto a los géneros que más visualización tienen son las noticias y películas, en oposición a la disminución de deporte (no se están realizando competiciones deportivas). El promedio de consumo diario es de 3 horas y 40 minutos. Si bien el encendido y tiempo de visionado se ha incrementado desde que se declaró el aislamiento obligatorio, en la primera semana se registró el consumo más alto y luego comenzó a disminuir.

Un dato interesante es el consumo de televisión según las diferentes generaciones. Los datos demuestran que las llamadas generaciones boomers and silent, es decir, las personas de mayor edad consumen un promedio de 5 horas 15 minutos de televisión diaria, es la población que tiene mayor riesgo ante el avance del virus, en consecuencia, creemos relevante que los protocolos y reflexiones en torno a la televisión tengan en cuenta que dicha población es la que más la consume. En ese sentido son interesantes las recomendaciones sobre "Cómo comunicar sobre el coronavirus" realizado por el Defensoría del Público, entre otras cuestiones se advierte sobre no llamar "abuelos/as o jubilados/as a las personas mayores" $(2020$, p. 2). Continuando con la cantidad de consumo de televisión según la franja etaria, la generación X (1965-1980) son los que siguen en la cantidad de horas con un promedio diario de 3 horas 45 minutos. Los

\footnotetext{
${ }^{7}$ Fuente: Kantar Ibope - Total INDIVIDUOS 6 a 30 hs. Lu a Do CABA-GBA - TV sin duplicación - 2 de marzo-19 de abril 2020 - Universo 11.721.959 personas - Análisis por semana.
} 
millennials (1981-1996) 2 horas 30 minutos, las niñas y niños 2 horas y 18 minutos y la generación Z (1996-2010) 1 hora 36 minutos. Los datos demuestran que cuanto más jóvenes el desplazamiento del consumo se traslada a otras pantallas y dispositivos, dejando la televisión como práctica de consumo audiovisual para los más grandes.

\subsection{GRILLAS DE PROGRAMACIÓN}

En este apartado nos interesa detenernos en el análisis de las grillas de programación para así observar qué se está ofreciendo. Algunas consideraciones previas: de los seis canales los que más rating tienen son Telefé en primer lugar, seguido por Canal 13, Canal 9, América TV, Televisión Pública y Net TV según el informe de Ignis Media Agency (2020). Como se mencionó en el apartado metodológico, el relevamiento y sistematización de las grillas de programación se realizó sobre la base de una metodología utilizada previamente (Heram, 2020). La muestra se tomó al mes de iniciado el ASPO, está conformada por la programación de los canales durante las 24 horas de la semana del domingo 19 al sábado 25 de abril. Cabe aclarar que a partir de la una de la mañana la programación de los canales se reitera o se emiten espacios publicitarios - "TV compras" - y programas religiosos - "Pare de Sufrir" - o se deja de transmitir.

De los seis canales, América TV fue el primero que inició la campaña \#yomequedoencasa, sacó del aire a Incorrectas y fue reemplazo por el programa Fantino a la tarde, dando un giro hacia la actualidad por sobre el espectáculo. La Televisión Pública -único canal de gestión estatal - fue el que más adaptó su programación, por un lado, porque transmite de lunes a viernes seis horas diarias de contenido educativo - Seguimos educando - a cargo del Ministerio de Educación de la Nación, y también sumó otros programas en sintonía con la coyuntura: Quedate en casa, Taller en casa, Unísono, la música va a tu casa.

En lo que respecto a las características generales de la programación, a partir de la muestra relevada del domingo 19 al sábado 25 de abril de los seis canales del área metropolitana, en cuanto a los porcentajes por tiempo de emisión de los diferentes tipos de discursos, los resultados arrojan los siguientes datos: prevalece en un $60 \%$ el 
discurso referencial, es decir aquellos que presentan concordancia con el campo externo según Orza (2002), le sigue con un $17 \%$ el discurso ficcional que son aquellos que tiene concordancia con "un campo de referencia (posible o fantástico)" (Orza, 2002, p. 138), con un $10 \%$ el discurso de hibridación que son aquellos que "combinan las formas de aproximación a la realidad externa y, al mismo tiempo, las formas que crean un universo de ficción" (Orza, 2002, p. 138) y un 3\% que denominamos "referencial / ficción" y es el contenido educativo Seguimos educando a cargo del Ministerio de Educación de la Nación que ofrece productos de ambos tipos de discursos. Los porcentajes restantes pertenecen a los horarios sin transmisión. A continuación, compartimos un gráfico de los minutos según tipo de discurso por cada uno de los canales.

Gráfico 1. Minutos según el tipo de discurso por canal.

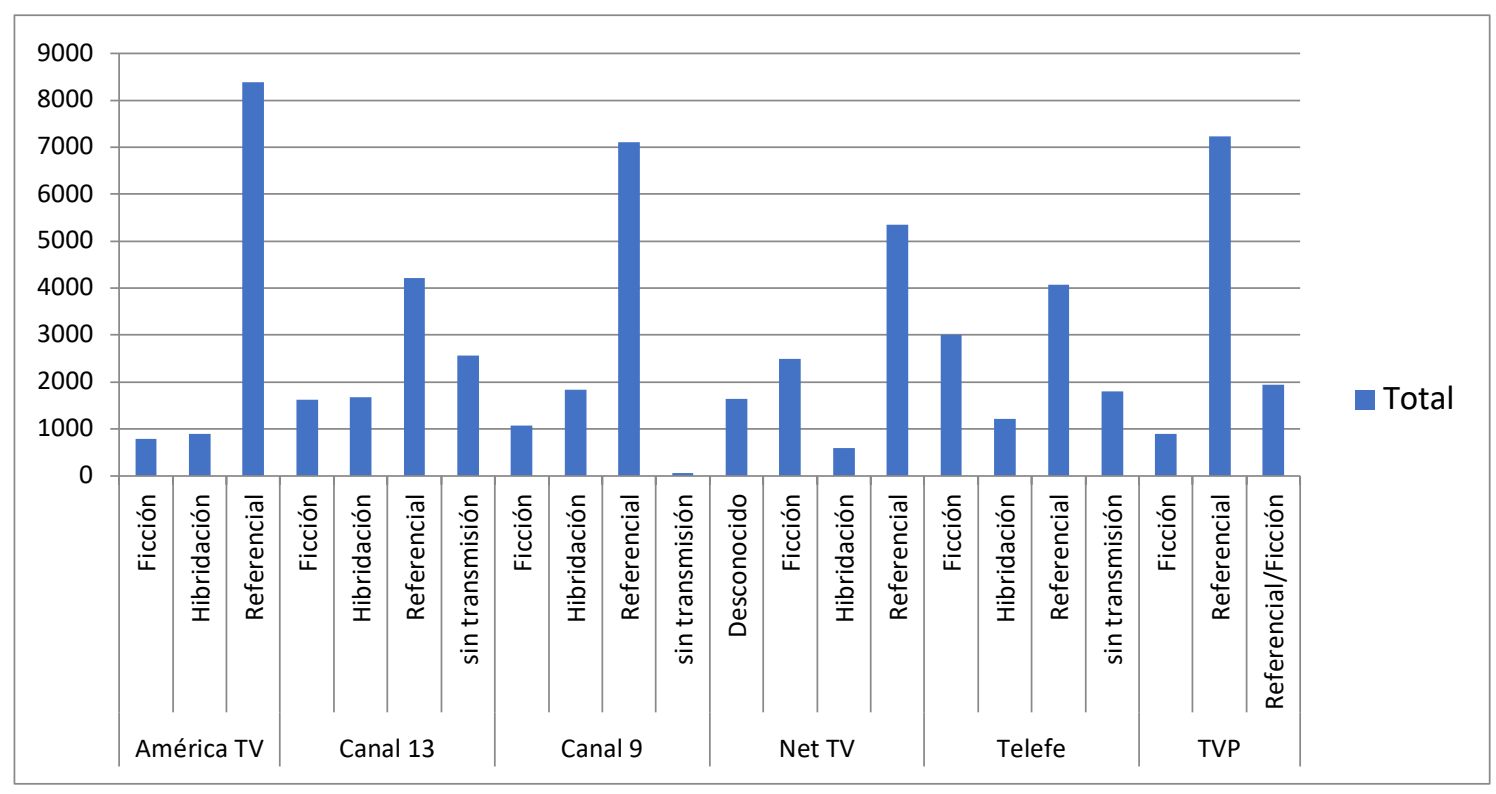

Fuente: Elaboración propia a partir de la muestra del 19 al 25 de abril de 2020.

Dentro de los discursos de tipo referencial podemos ubicar a los siguientes géneros: noticieros, debate político, documentales, periodístico, transmisión en directo de deporte, cultural, religioso, entre otros. Como se observa en el gráfico todos los canales tienen la mayor transmisión vinculada con el discurso referencial, no es un dato menor ya que en el contexto de pandemia no se está produciendo ficción local (sobre este punto retomaremos en breve). 
Un dato interesante a observar es cuáles son los géneros que más tiempo de pantalla ocupan. A continuación, compartimos un gráfico por minutos de pantalla según género televisivo en el total de la programación.

Gráfico 2. Minutos según el género televisivo en el total de la programación.

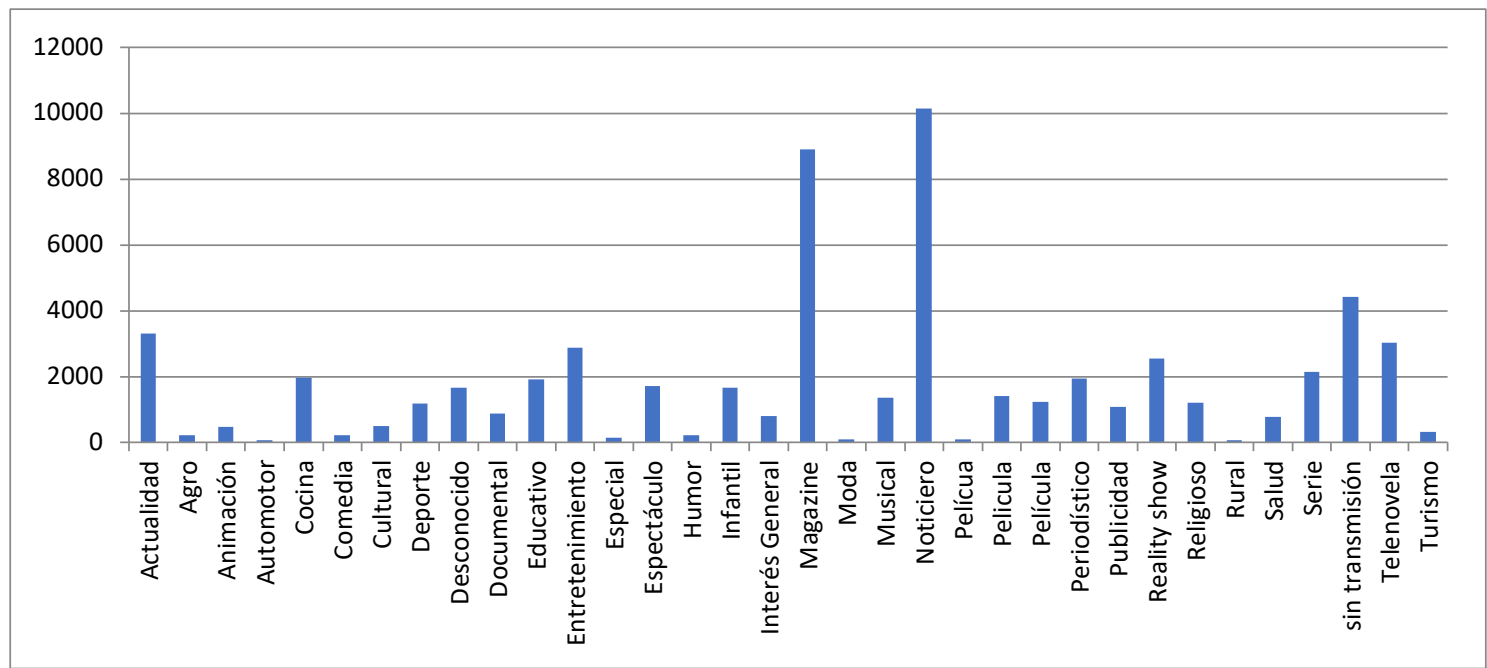

Fuente: Elaboración propia a partir de la muestra del 19 al 25 de abril de 2020.

El noticiero y el magazine son los géneros que más tiempo de pantalla tienen, esto no es un dato menor si lo relacionamos con los resultados sobre consumo de medios al que hacíamos referencia en el apartado anterior. El género que más se consume es el noticiero, ello también debe entenderse porque es el que más tiempo de pantalla tiene (en general hay cuatro emisiones: mañana, mediodía, noche y medianoche) y por ende las posibilidades de consumirlo se incrementan.

Otro aspecto a tener en consideración es el porcentaje de tiempo de emisión que tienen los productos por país de origen. Compartimos el siguiente gráfico: 
Gráfico 3. Porcentaje de tiempo de emisión por país de origen del producto. Total de la programación.

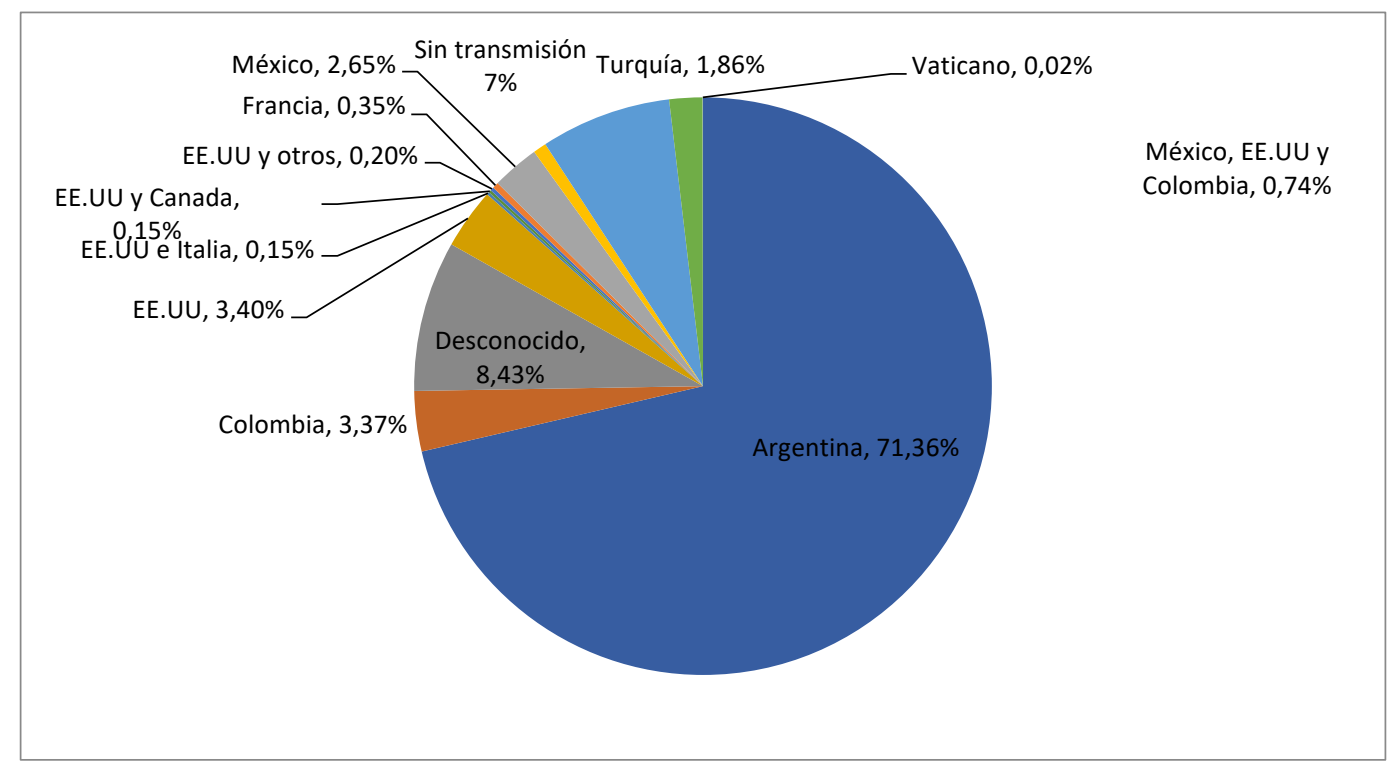

Fuente: Elaboración propia a partir de la muestra del 19 al 25 de abril de 2020.

Un dato a tener en consideración con respecto a la cuota de pantalla de productos locales de ficción es que, hasta el 20 de marzo, día que comenzó el ASPO, sólo estaba produciendo una ficción local en la televisión de aire, Separadas (Canal 13) a cargo de Polka. Tras el inicio del ASPO se detuvieron las grabaciones. Con el correr de los días se cristalizó la situación de crisis que transita la industria audiovisual, se estima que lo que resta del 2020 sólo se terminará de grabar -una vez que las condiciones sanitarias lo permitan- El tigre Verón de Polka dado que restan 15 días de rodaje. Polka ha tenido denuncias por parte de la Asociación Argentina de Actores por la falta de pagos de salarios y aportes a la obra social. Esta situación lleva a una disputa, que se está desarrollando en los medios sobre la cuota de pantalla para ficciones locales en la televisión, entre otros puntos de debate: altos sueldos de las primeras figuras, desplazamiento de las ficciones a otras plataformas, etc. (Respigui, 2020).

Otra variable que se utilizó para analizar la programación es el tiempo de emisión en directo o grabado. Los trabajos que reflexionan sobre el fin de la televisión como medio 
masivo (Verón, 2009; Carlón, 2009; Carlón y Scolari, 2009; Piscitelli, 1998; Pérez de Silva, 2000, entre otros) entienden que el directo televisivo, es decir la transmisión en directo de acontecimientos y/o eventos (políticos, deportivos, etc.) iba a continuar generando discursos masivos a gran escala. Es decir que el directo resistiría los cambios en la televisión. En este sentido interesa detenernos en dos cuestiones, por un lado, la gran expectativa - desde el 12 de marzo a la fecha de escritura del artículo- que han generado las conferencias de prensa, anuncios y cadena nacional por parte del presidente ${ }^{8}$. Estos acontecimientos político-mediáticos tienen la particularidad, en un contexto sanitario de emergencia y de aislamiento, de generar una gran expectación por parte de la ciudadanía, en cada uno de ellos se informa sobre las nuevas medidas y el devenir de la cuarentena. Ocurren cada 9 días en promedio, es decir que un acontecimiento extraordinario de este tipo genera en los medios una gran cantidad de información en directo. De allí también que pueda interpretarse los datos sobre el consumo mencionado en el apartado anterior.

En relación con lo anterior un dato a tener en cuenta es el porcentaje del directo televisivo. El $41 \%$ de la programación total es en directo y el 52\% grabado, el resto pertenece al segmento sin trasmisión. Cabe aclarar que, al reiterarse a partir de la una de la mañana los productos ya emitidos, hace que el porcentaje del grabado se incremente. Compartimos un gráfico con minutos de tiempo de pantalla de productos grabados y en directo por cada emisora.

\footnotetext{
${ }^{8} 12 / 03 / 20$ cadena nacional, $15 / 03 / 20$ y 19/03/20 conferencia de prensa, 29/03/20 anuncio, 10/04/20 conferencia de prensa, $25 / 04 / 20$ anuncio, $08 / 05 / 20$ y $23 / 05 / 20$ conferencia de prensa.
} 
Gráfico 4. Minutos de tiempo de pantalla de productos grabados y en directo por cada emisora

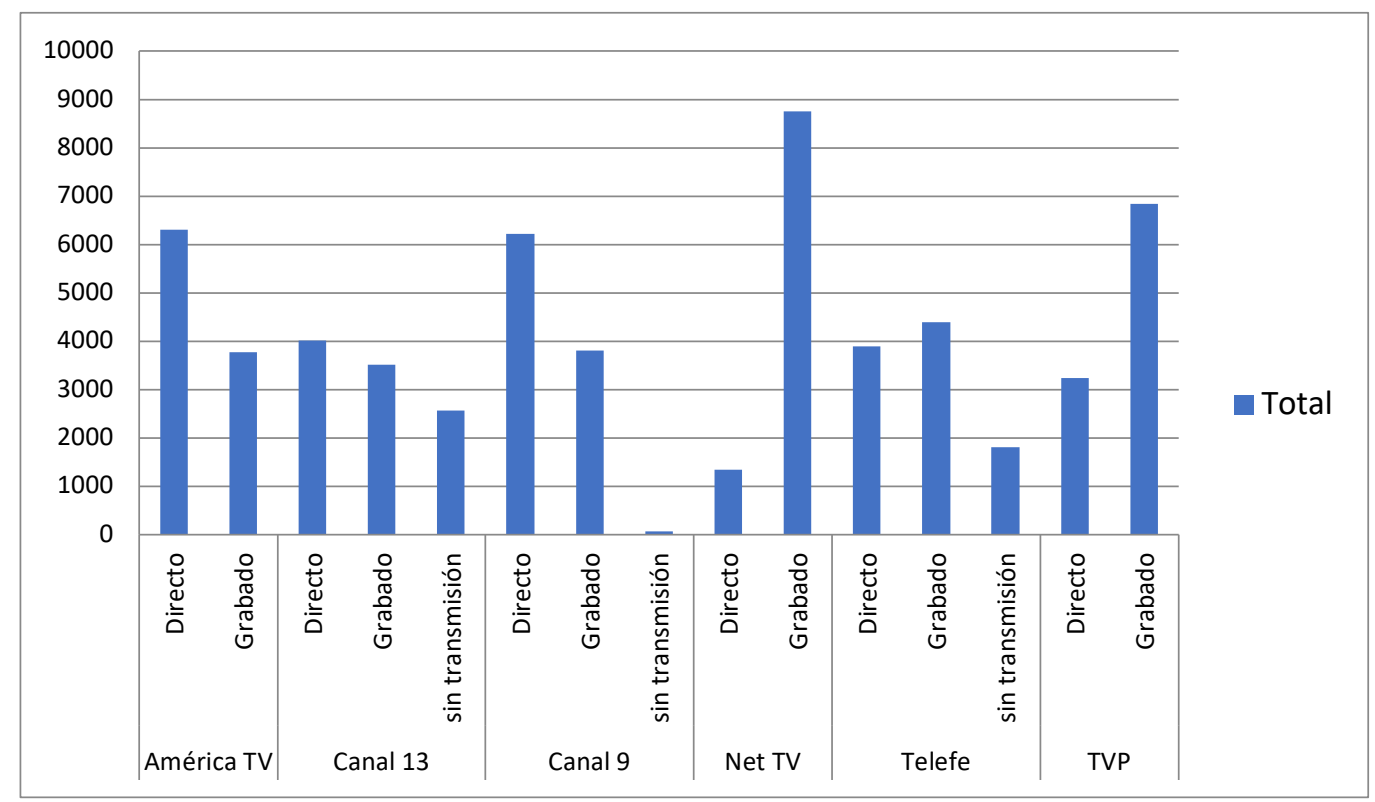

Fuente: Elaboración propia a partir de la muestra del 19 al 25 de abril de 2020.

Por último, nos detenemos en el horario de mayor encendido - prime time- que en Argentina es desde las 20:00 hasta la medianoche, interesa observar qué tipo de discursos y géneros son los que prevalecen, así como el porcentaje de emisión en directo o grabado. En cuanto a los tipos de discursos los resultados arrojan los siguientes datos: el $67 \%$ de tiempo de emisión de los seis canales se corresponde con el discurso referencial, el $22 \%$ de ficción y el $11 \%$ de hibridación. A continuación, compartimos un gráfico de los minutos por tipo de discurso y canal. 
Gráfico 5. Minutos de tiempo de pantalla de productos grabados y en directo por cada emisora

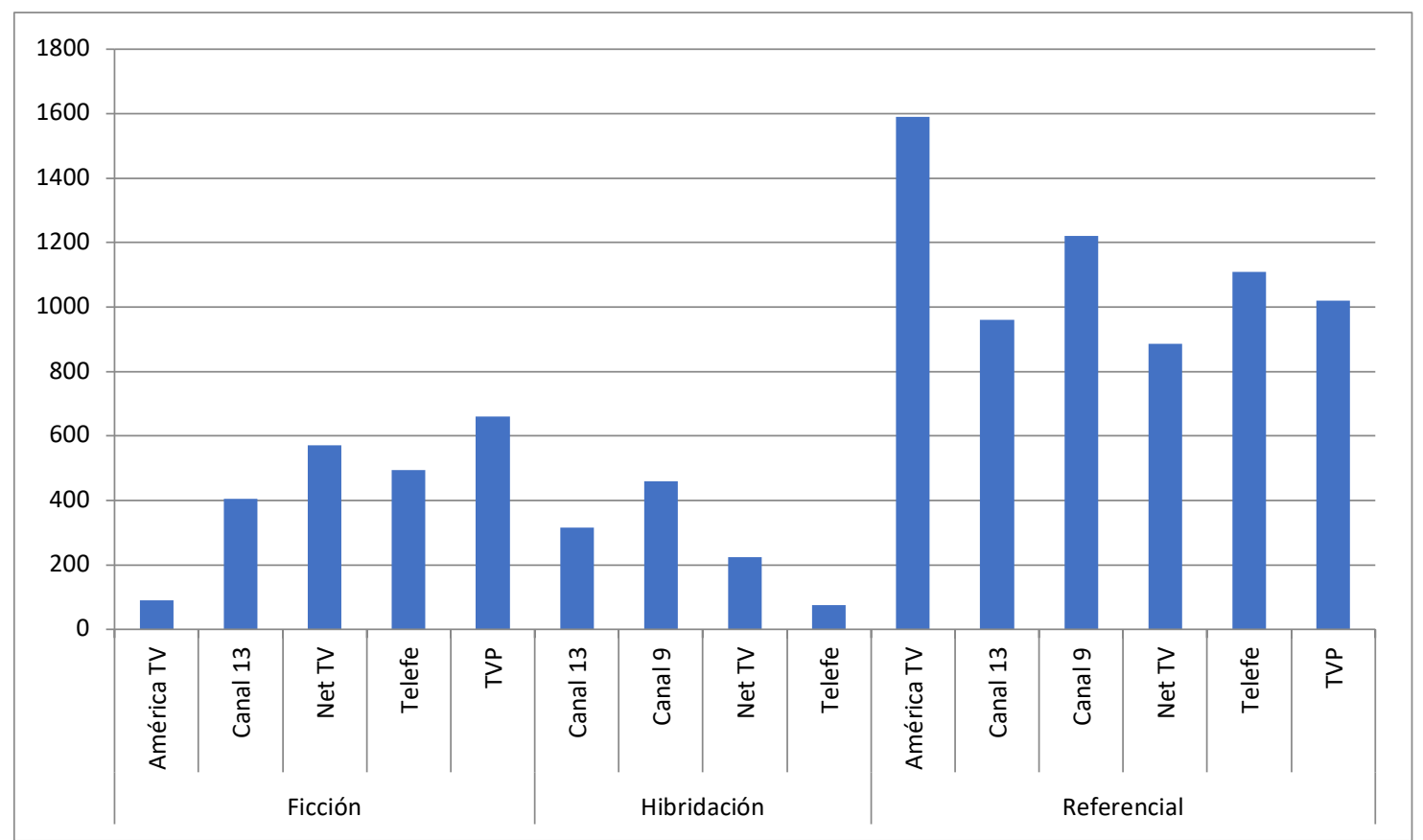

Fuente: Elaboración propia a partir de la muestra del 19 al 25 de abril de 2020.

Como se desprende del gráfico en todos los canales prevalece el discurso referencial, siendo América TV la emisora que mayor tiempo le dedica a este tipo de discurso, ello está en relación con que el canal casi no transmite ficción (dibujos animados los fines de semana y eventualmente alguna película), y su programación está organizada en torno al panelismo televisivo y al directo (Heram, 2018). Con respecto a los géneros que prevalecen en el prime time, se encuentra en primer lugar con un $25 \%$ los noticieros, en segundo lugar, con un $19 \%$ los programas de actualidad, $12 \%$ películas y $10 \%$ magazines. En consonancia con los datos arrojados el $62 \%$ de la programación es en directo y el $38 \%$ grabada. En este contexto de pandemia en el horario de mayor encendido se emiten programas que desde sus diferentes géneros se ocupan de "la realidad" y en especial de tematizar sobre la pandemia.

\section{CONCLUSIONES}

A lo largo del artículo nos interesó observar algunas de las características de la televisión actual en el contexto de pandemia y asilamiento social, preventivo y obligatorio como 
el que se está viviendo en Argentina. Partimos de entender que los medios de comunicación cumplen un rol clave, que es el de informar y desde este lugar garantizar el derecho a la información, en un contexto de crisis sanitaria en el que la incertidumbre genera temor y ansiedad, en paralelo la necesidad de información aumenta y por ende la televisión, pero también otros medios y redes sociales han aumentado su consumo.

A partir del visionado de la televisión, en especial de los géneros no ficcionales, describimos algunas de las tendencias predominante en este contexto particular, entre las más retiradas observamos: la tensión entre los tiempos de la televisión y los tiempos de la ciencia, la circulación de médicos y especialistas por los programas, la fuerte presencia del panelismo en la construcción de binomios dicotómicos con un leve giro hacia las preguntas, la promoción de la vigilancia y el punitivismo por parte del medios así como la presencia de las historias de vida en la pantalla, todas estas tendencias si bien no son novedosas se reconvirtieron en un contexto de pandemia y cuarentena generando un mensaje de incertidumbre. Por otra parte, también identificamos algunas cuestiones nuevas, por un lado a nivel estético el uso partido de la pantalla al estilo zoom, por otra parte una convergencia discursiva que duró pocos días en el que primó un discurso del consenso y por último, como los números lo demuestran, el incremento del consumo televisivo, en especial en los adultos mayores.

También nos detuvimos en caracterizar la programación televisiva de los seis canales de aire, los resultados demuestran la fuerte presencia de discursos referenciales en especial noticieros y magazines, cuestión que coincide con el género que más se consume. Ello también se reitera en el horario de mayor encendido siendo el directo televisivo el que predomina, todo ello nos lleva a reflexionar sobre las tendencias de la televisión, un medio que estaba en descenso de consumo y que por esta extraordinario situación ha vuelto a ganar audiencia. Las preguntas que nos interesan seguir realizando a partir de este primer diagnóstico están en relación con la instancia de la recepción, es decir de qué manera, en especial los adultos mayores, consumen y perciben aquello que se emite. Creemos que realizar entrevistas en profundidad aportaría a comprender, en este entramado de mediatización, la manera en que los sentidos circulan socialmente y así poder pensar nuevas formas para comunicar en situación de crisis. 


\section{REFERENCIAS BIBLIOGRÁFICAS}

AA.VV. (2020). ¿Cómo nos informamos durante la cuarentena? Tecnología, noticias y entretenimiento en tiempos de aislamiento por el COVID-19. Grupo CPS. Disponible en http://www.comunicacionyseguridad.com/covid-19-entre-la-desconfianza-en-lasnoticias-y-el-entretenimiento-online/

AA.VV. (2020). El consumo de medios en un entorno extraordinario. Buenos Aires: Ignis Media Agency. Disponible en https://www.totalmedios.com/PublicFiles/files/Ignis-Covid.pdf

AA.VV. (2020). Relevamiento del impacto social de las medidas de aislamiento dispuestas por el PEN. Buenos Aires: CONICET. Disponible en https://www.conicet.gov.ar/wp-content/uploads/Informe Final Covid-Cs.Sociales1.pdf

AA.VV. (2020). Recomendaciones para la cobertura de la pandemia COVID-19. Buenos Aires: Defensoría del Público de Servicios de Comunicación Audiovisual. Disponible en https://defensadelpublico.gob.ar/recomendaciones-para-la-cobertura-de-lapandemia-covid-19/

AA.VV. (2017). Encuesta sobre consumos culturales 2017. Sistema de información cultural de la Argentina. Ministerio de Cultura, Presidencia de la Nación. Disponible en https://www.sinca.gob.ar/VerDocumento.aspx?/dCategoria=10

Bourdieu, P. (1997 [1996]). Sobre lo televisivo. Barcelona: Anagrama.

Carlón, M. (2009). ¿Autopsia a la televisión? Dispositivo y lenguajes en el fin de una era. En Carlón, M y Scolari, C. A. (Eds), El fin de los medios masivos. El comienzo de un debate (pp. 159-187). Buenos Aires: La Crujía.

Carlón, M y Scolari, C. A. (Eds). (2009). El fin de los medios masivos. El comienzo de un debate. Buenos Aires: La Crujía 
Carlón, M. (2016). Después del fin. Una perspectiva no antropocéntrica sobre la posttv, el post-cine y y youtube. Ciudad Autónoma de Buenos Aires: La Crujía.

Denzin, N. y Lincoln, Y. (2003). Strategies of qualitative inquiry. New Delhi y Londres: Sage y Thousand Oaks.

Fernández, J. L. (2020). Un presidente entre la pandemia y el postbroadcasting. Revista Question (1), 1-27. https://doi.org/10.24215/16696581e301

Foucault, M. (1978). Seguridad, territorio y población. Buenos Aires: Fondo de la Cultura Económica.

Hall, S. (1980). Codificar/decodifcar. En Culture, Media and Language. Londres: Hutchinson. Traducción Silvia Delfino.

Heram, Y. (2018). Televisión Pública: un estudio exploratorio de su programación. Estudos em Comunicação, 26(1), 65-80. https://doi.org/10.20287/ec.n26.v1.a05

Heram, Y. (2018). Intratables: el panelismo de "todas las voces todas". Revista Pilquen. Sección Ciencias Sociales, 21(2), 54-68. Disponible en http://revele.uncoma.edu.ar/htdoc/revele/index.php/Sociales/article/view/1905

Heram, Y. (2020). Cambios en la Televisión Pública Argentina. Revista Internacional de Comunicación y Desarrollo (RICD), 3(12), 20-35.

https://doi.org/10.15304/ricd.3.12.6426

Kleis Nielsen, R., Fletcher, R., Newman, N. Brennen, J. S. and Howard, P. N. (2020). Navigating the 'Infodemic': How People in Six Countries Access and Rate News and Information about Coronavirus. Oxford: Reuters Institute. Disponible en https://reutersinstitute.politics.ox.ac.uk/sites/default/files/202004/Navigating\%20the\%20Coronavirus\%20Infodemic\%20FINAL.pdf Martín-Barbero, J. (1987). De los medios a las mediaciones. Barcelona: Gustavo Gilli. Orza, G. (2002). Programación televisiva. Un modelo de análisis instrumental. Buenos Aires: La Crujía. 
Pérez de Silva, J. (2000). La televisión ha muerto. La nueva producción audiovisual en la era de Internet: la tercera revolución industrial. Barcelona: Gedisa.

Piscitelli, A. (1998). Post/Televisión. Buenos Aires: Paidós.

Reporteros sin Fronteras. (2019) ¿Quiénes son los dueños de los medios en Argentina? Buenos Aires. Disponible en http://argentina.mom-rsf.org/es/

Respigui, E. (13 de mayo de 2020). Polka cancela Separadas y se abre la discusión sobre el futuro de la ficción argentina. Página/12. Disponible en https://www.pagina12.com.ar/265362-polka-cancela-separadas-y-se-abre-ladiscusion-sobre-el-futu

Rincón, O. (2010). La obsesión porque nos amen: crisis del periodismo/éxitos de los telepresidentes. En Amado, A. (2010). La palabra empeñada. Investigaciones sobre medios y comunicación pública en Argentina (13-16). Buenos Aires: Fundación Friedrich Ebert.

Valdettaro, S. (2010). Subjetividades y digitalización: bosquejo de un estado de la cuestión. En Mediatización, sociedad y sentido: diálogos entre Argentina y Brasil. Departamento de Ciencias de la Comunicación, Escuela de Comunicación Social. Facultad de Ciencia Política y RR. II. Universidad Nacional de Rosario Verón, E. (2009). El fin de la historia de un mueble. En Carlón, M. y Scolari, C. A. (Eds). El fin de los medios masivos. El comienzo de un debate (pp. 229-248). Buenos Aires: La Crujía. 